\title{
Ergenlerde Akran Baskısı ve Riskli Davranışlar Arasındaki İlişkinin İncelenmesi
}

\author{
Ertuğrul TALU \\ Kırşehir Ahi Evran Üniversitesi \\ etalu@ahievran.edu.tr \\ ORCID ID: 0000-0002-3062-6130 \\ Gökhan GÜMÜŞ \\ Milli Eğitim Müdürlüğü, Malatya \\ gokhangumus2357@gmail.com \\ ORCID ID: 0000-0002-4161-0425
}

\begin{tabular}{lrr} 
Araştırma Makalesi & DOI: $10.31592 /$ aeusbed.709641 \\
\hline Geliş Tarihi: 26.03 .2020 & Revize Tarihi: 23.06.2020 & Kabul Tarihi: 26.06.2020
\end{tabular}

\section{Atıf Bilgisi}

Talu, E. ve Gümüş, G. (2020). Ergenlerde akran baskısı ve riskli davranışlar arasındaki ilişkinin incelenmesi. Ahi Evran Üniversitesi Sosyal Bilimler Enstitüsü Dergisi, 6(2), 390-403.

\section{ÖZ}

$\mathrm{Bu}$ araştırmada ergenlerde akran baskısı ve riskli davranışlar arasındaki ilişkilerin çeşitli değişkenler açısından incelenmesi amaçlanmıştır. Araştırma modeli olarak ilişkisel tarama deseni kullanılan bu araştırmanın çalışma grubunu, 2019 - 2020 eğitim öğretim yılında Malatya ilinde 4 devlet lisesinde eğitim gören 392 öğrenci (199 kız, 193 erkek) oluşturmuştur. Verilerin toplanmasında Esen-Kıran (2003) tarafından geliştirilen "Akran Baskısı Ölçeği”" ile Gençtanırım ve Ergene (2014) tarafından geliştirilen "Riskli Davranışlar Ölçeği”" kullanılmıştır. Araştırmada akran baskısı ve riskli davranışlar arasındaki ilişkiyi ortaya koymak için Pearson momentler çarpımı korelasyon katsayısı, akranlarla geçirilen süre, akran baskısı ve riskli davranışlar arasındaki ilişki için Spearman Brown sıra farkları korelasyon katsayısı, akran baskısı ve riskli davranışların cinsiyet göre farklılaşmasını ortaya koymak için de t testi ve Mann Whitney $U$ Testi kullanılmıştır. Araştırmadan elde edilen bulgulara göre ergenlerde akran baskısı ile riskli davranışlar arasında düşük ve orta düzeyde pozitif anlamlı ilişkiler bulunduğu görülmüştür. Bu ilişkiler doğrudan akran baskısında antisosyal davranış, intihar eğilimi, beslenme alışkanlıkları ve alkol kullanımında düşük düzeyde iken sigara kullanımı ve okul terkinde orta düzeyde görülmektedir. Bunun yanında dolaylı akran baskısının intihar eğilimi, beslenme alışkanlıkları ve alkol kullanımında düşük düzeyde bir ilişki görülürken antisosyal davranışta, sigara kullanımında ve okul terkinde orta düzeyde bir ilişki görülmektedir.

Anahtar Sözcükler: Ergenlik, akran baskısı, riskli davranışlar.

\section{Investigation of the Relationship Between Peer Pressure and Risky Behaviors in Adolescents}

\begin{abstract}
In this study, it was aimed to examine the relationships between peer pressure and risky behaviors in adolescents in terms of various variables. The study group of this research, which uses a relational screening model as a research model, consists of 392 students (199 girls, 193 boys) studying in 4 state high schools in Malatya in the 2019-2020 academic year. "Peer Pressure Scale" developed by Esen-Kiran (2003) and "Risky Behavior Scale" developed by Gençtanırım and Ergene (2014) were used to collect the data. To reveal the relationship between peer pressure and risky behaviors in the research, to reveal the gender differentiation of risky behaviors, Pearson moments multiplication correlation coefficient, Spearman Brown rank correlation coefficient for peer pressure and the relationship between risky behavior, T test and Mann Whitney U Test was used. According to the findings obtained from the study, it was observed that there were low and moderate positive significant relationships between peer pressure and risky behaviors in adolescents. These relationships are low in peer pressure, antisocial behavior, suicidal tendencies, nutritional habits and alcohol use, but are moderate in smoking and school dropout. In addition, there is a low correlation between indirect peer pressure, suicidal tendency, eating habits, and alcohol use, while there is a moderate relationship between antisocial behavior, smoking and school dropout.
\end{abstract}

Keywords: Adolescence, peer pressure, risky behaviors.

\section{Giriş}

Ergenlik dönemi, insan gelişiminde çatışma ve karmaşaların en üst düzeyde yaşandığı bir geçiş dönemi olarak görülmektedir. Bu dönem içerisinde bireyler hem fiziksel hem de psikolojik 
olarak ani ve yoğun değişiklikler yaşamaktadır. Yaşanılan bu zorlu değişimler içerisinde bireyler artık çocukluk çağından çıkıp bir ucu yetişkinliğe kadar uzanacak bir gelişim yolculuğuna koyulmaktadırlar.

Diğer yandan ergenlik dönemi gerek gelişim süreci gerekse ortaya çıkardığı sonuçlar bakımından, hem bireye hem de çevresine yansımaları olan kritik ve önemli bir gelişim dönemidir (Şimşek ve Çöplü, 2018). Bu dönemle birlikte bireyler çevrelerindeki diğer bireylerle çocukluk yıllarından çok daha farklı bir şekilde yeni ilişkiler kurma eğilimi içerisine girerler ve bu ilişkiler içerisinde şüphesiz en özel ve etkili olanı ise akranlarıyla kurdukları ilişkilerdir (Bayhan ve Işıtan, 2010; De Goede, Branje, Delsing ve Meeus, 2009). Akranlarla kurulan bu ilişkiler aynı zamanda ergenlerin bu dönemde karşılaşabileceği sorunların üstesinden gelmesinde ve yetişkin rolüne hazırlanmasında önemli yer tutabilmektedir (Dornbusch, 1989).

Ergenlikte akran gruplarının ve ilişkilerinin olumlu olarak birçok işlevleri olmasına rağmen ergen üzerindeki olumsuz etkileri de azımsanmayacak şekilde kendisini gösterebilmektedir (Esen, 2003). Akran ilişkilerinde yaşanabilecek bu olumsuzluklardan bir tanesi de kuşkusuz akran baskısıdır (Aktuğ, 2006). Akran baskısı, kişinin bir şeyle ilgili istek ve fikrinin çok da önemli olmadığı ancak akranlarının istek ve fikirlerinin bir baskı aracı olarak kişi üzerinde etkili olması olarak tanımlanmaktadır (Clasen ve Brown, 1985).

$\mathrm{Bu}$ bağlamda ergenlik dönemi ile birlikte bireyler daha önceki hayatlarından öğrendikleri normlardan, kurallardan uzaklaşabilmekte ve hatta terk edilebilmektedirler. Bu duruma neden olan temel olguların başında ise yine akran baskısı gelmektedir. Bu yönüyle akran baskısı genellikle gruba ve grup normlarına bağlılığı temel almaktadır (Vander Zanden, Crandell ve Crandell, 2000). Berndt ve Ladd (1989) akran baskısının ödül ve ceza sistemi üzerinden işlediğini belirtmektedir. Grup normlarına uyan bireyler ödüllendirilirken uymayan bireyler çeşitli şekillerde cezalandırılmaktadırlar. Buradaki cezalandırma gruptan dışlamak olarak görülürken ödüllendirme ise grupta kabul görme ve söz sahibi olma şeklinde görülebilmektedir.

Ergenlik döneminde akranların birbirlerine olan etkisi bazı durumlarda doğrudan görülürken bazı durumlarda da dolaylı yollarla olabilmektedir. Akranların doğrudan etkileri daha çok komut verir tarzda ve emir cümleleri biçiminde olurken dolaylı yollarla uygulamaları ise model olma ve davranış1 özendirme şeklinde olabilmektedir (Clasen ve Brown, 1985). Doğrudan akran baskısı daha kolay gözlemlenebilirken dolaylı akran baskısını gözlemlemek daha zor olabilmektedir (Savin-Williams ve Berndt, 1990). Diğer yandan ergenlerde hem doğrudan hem de dolaylı akran baskısı cinsiyete göre anlamlı düzeyde farklılaşmaktadır. Erkek cinsiyette olma ergenlerde akran baskısını anlamlı düzeyde arttırmaktadır (Kapıkıran ve Fiyakalı, 2005).

Ergenler üzerinde akran gruplarının etkisi pek çok alanda kendini gösterebilmektedir. Özellikle de bu etkisinin olumsuz olduğu durumlarda ergenin pek çok davranış ve tutumu bundan olumsuz etkilenmekte ve bu durum ergenlerde bir dizi olumsuz / riskli davranışın görülmesine sebep olabilmektedir (Şahin ve Özçelik, 2016). Riskli davranışlar olarak da adlandırılan bu davranışlar aynı zamanda ergenin sosyal, duygusal ve fiziksel gelişimi açısından çeşitli riskleri barındırmaktadır (Austin ve Sciarra, 2017).

Konuyla ilgili yapılan araştırmalar incelendiğinde özellikle riskli davranışlar olarak nitelenebilecek alkol, sigara, uyuşturucu, intihar, okul terki, çeteleşme, zorbalık ve daha birçok olumsuz davranışların bazı ergenler tarafından benimsendiği görülmektedir (Chımwamurombe, 2011; Gül ve Güneş, 2009). Bu davranışları bir şekilde benimsemiş ve yaşam biçimine yerleştirmiş ergenler bunları çevrelerindeki diğer akran gruplarına da bulaştırmakta ve bulaştırıcılık esnasında direnç gösteren akranlarına ise baskı ve zorbaca davranışlar uygulayabilmektedir.

Kıran-Esen'e (2003) göre, ergenlerde akran baskısı arttıkça risk alma davranışlarının da artış gösterdiği gözlemlenmektedir. Bu durum akran baskısının ergenlerin risk davranışını yönlendiren önemli değişkenlerden biri olduğunu ortaya koymaktadır. 
Görüldüğü gibi ergenlik dönemi ile birlikte akran ilişkileri ergenin hayatında belirleyici bir rol oynamaya başlamaktadır. Akran grupları ergen gelişimi açısından her ne kadar önemli olsa da belirli durumlarda risk faktörlerini de arttırmaktadır ve bu da ergenler için büyük tehlikeleri de beraberinde getirebilmektedir (Alikaşifoğlu ve Ercan, 2009).

İşte bu çalışmada ergenlerde akran baskısı ve riskli davranışlar arasındaki ilişkilerin çeşitli değişkenler açısından ortaya konulması amaçlanmıştır. Bu yönüyle çalışmanın literatüre önemli katkılar sağlayacağı düşünülmektedir.

\section{Yöntem}

Bu bölümde araştırmanın modeli, çalışma grubu, veri toplama araçları ve verilerin analizine ilişkin detaylı bilgiye yer verilmiştir.

\section{Araștırma Modeli}

Ergenlerde akran baskısının riskli davranışlarla olan ilişkisini ortaya çıkarmayı amaçlayan bu araştırmada genel tarama modellerinden ilişkisel tarama modeli kullanılmıştır. İlişskisel tarama modelleri iki veya daha çok sayıdaki değişken arasındaki değişimin varlığı ve derecesini belirlemeyi amaçlamaktadır (Karasar, 2018).

\section{Çalışma Grubu}

Araştırmanın çalışma grubu, 2019 - 2020 eğitim-öğretim yılında Malatya ilinde 4 devlet lisesinde eğitim gören 392 öğrenciden (199 kız, 193 erkek) oluşmaktadır. Çalışma grubunun belirlenmesinde rastgele örnekleme yöntemi kullanılmıştır (Büyüköztürk, 2017; Büyüköztürk, Kılıç Çakmak, Akgün, Karadeniz ve Demirel, 2016).

\section{Veri Toplama Araçları}

Araştırma sürecinde ilk olarak literatür taraması yapılmış ve literatürde araştırma değiş̧kenlerini ölçmek için geliştirilmiş olan ölçme araçları belirlenmiştir. Sonrasında belirlenen ölçme araçlarının geliştiricilerine ulaşılmış ve gerekli kullanım izinler alınmıştır. Daha sonra çalışmanın yapılacağ1 Malatya İli İl Milli Eğitim Müdürlüğüne başvuruda bulunulmuş ve 11.03.2020 tarihli Anket-Tez Araştırma ve Değerlendirme Komisyonu etik uygunluk kararı ve 61316475-44-E.5459251 sayılı Malatya İl Milli Eğitim Müdürlüğü oluru ile anket uygulaması etik izni alınmıştır. Araştırma sürecinin tamamında tüm bilimsel araştırma ve etik kurallarına uyulmuştur.

$\mathrm{Bu}$ araştırmada veriler; Kişisel Bilgi Formu, Akran Baskısı Ölçeği ve Riskli Davranışlar Ölçeği kullanılarak toplanmıştır.

\section{Kişisel Bilgi Formu}

Araştırmacılar tarafından geliştirilmiş olan kişisel bilgi formunda katılımcıların cinsiyetleri ve akranlarıyla geçirdikleri okul dışı süre (saat) hakkında bilgi edinmeyi amaçlayan sorulara yer verilmiştir. Akranlarla geçirilen okul dışı süre belirlenirken ergenlerden hafta içi ve hafta sonu farkına dikkat etmeleri, buna göre kendilerine uygun ortalama bir cevabı vermeleri istenmiştir. Bu durumun belirtilme nedeni okulda geçirilen mecburi sürenin değil de okul dışında geçirilen gönüllü sürenin daha güvenilir sonuçlar vereceğidir. Öğrencilerin soruları daha rahat cevaplaması için kişisel bilgi formunda ad, soyad, okul numarası gibi özel bilgiler içeren sorulara ver verilmemiştir.

\section{Riskli Davranışlar Ölçeği}

$\mathrm{Bu}$ araştırmada ergenlerde riskli davranışları ölçmek amacıyla Gençtanırım ve Ergene (2014) tarafından geliştirilen "Riskli Davranışlar Ölçeği” kullanılmıştır. 36 maddeden oluşan bu ölçekte 
antisosyal davranış (7 madde), alkol kullanımı (7 madde), sigara kullanımı (6 madde), intihar riski (4 madde), riskli beslenme davranışları (5 madde) ve okul terki (7 madde) olmak üzere ergenlik döneminde görülen 6 risk faktörü ölçülmektedir. 5'li likert tipinde hazırlanan bu ölçeğin alfa güvenilirlik katsayısı 0.91 olarak bulunmuştur. Ölçekten elde edilen yüksek puanlar yüksek risk faktörüne işaret etmektedir.

\section{Akran Baskısı Ölçeği}

Ergen davranışı üzerinde akranlarının baskısının incelenmesi amacıyla Kıran-Esen (2003) tarafından geliştirilen "Akran Baskısı Ölçeği” kullanılmıştır. 34 maddeden oluşan bu ölçme aracının 19 maddesi direkt akran baskısını 15 maddesi dolaylı akran baskısını ölçmektedir. Doğrudan akran baskısı alt faktörü için alfa güvenilirlik katsayısı 0.89 , dolaylı akran baskısı alt faktörü için alfa kat sayısı 0.82 'dir. Ölçekten elde edilen yüksek puanlar yüksek akran baskısına işaret etmektedir.

\section{Verilerin Analizi}

Araştırmada akran baskısı (doğrudan ve dolaylı) ve riskli davranışlar (antisosyal davranış ve okul terki riski) arasındaki ilişkiyi ortaya koymak için parametrik testlerden Pearson Momentler Çarpımı Korelasyon Katsayısı (r); akranlarla geçirilen süre, akran baskısı (doğrudan ve dolaylı) ve riskli davranışlar (alkol, sigara ve okul terki) arasındaki ilişkinin ortaya konması için nonparametrik testlerden Spearman Brown Sıra Farkları Korelasyon Katsayısı $\left(\mathrm{r}_{\mathrm{s}}\right)$ kullanılmıştır. Akran baskısı ve riskli davranışların cinsiyet göre farklılaşmasını ortaya koymak için parametrik testlerden ilişkisiz örneklemler için $t$ testi ve nonparametrik testlerden Mann Whitney U Testi kullanılmıştır. Verilerin çözümlenmesi sürecinde IBM tarafindan geliştirilen SPSS 21 paket programı kullanılmıştır. Verilerin yorumlanması süreci alan yazına uygun olarak yapılmıştır (Büyüköztürk, 2017; Büyüköztürk, Çokluk ve Köklü, 2016).

\section{Bulgular}

Bu bölümde elde edilen bulgulara alt problemlere göre sırasıyla yer verilmiştir.

\section{Betimsel İstatistikler}

$\mathrm{Bu}$ araştırmada akran baskısı (doğrudan ve dolaylı) ve riskli davranışlar (antisosyal davranış, alkol kullanımı, sigara kullanımı, intihar eğilimi, beslenme alışkanlıkları, okul terki) arasındaki ilişki ortaya konmuştur. Değişkenlerin betimsel istatistikleri Tablo 1'de verilmiştir.

Tablo 1

Betimsel istatistikler $(N=392)$

\begin{tabular}{lcccc}
\hline & \multicolumn{4}{c}{ İstatistiki Değerler } \\
\cline { 2 - 5 } & Ortalama & Standart Sapma & $\begin{array}{c}\text { Çarpıklık } \\
\text { Katsayısı }\end{array}$ & Basıklık Katsayısı \\
\hline Doğrudan Akran Baskısı & 21.77 & 3.32 & 1.44 & 1.45 \\
Dolaylı Akran Baskısı & 20.89 & 5.78 & 1.24 & 1.20 \\
Antisosyal Davranışlar & 14.31 & 5.22 & 1.09 & 1.36 \\
Alkol Kullanımı & 8.10 & 3.80 & 4.52 & 22.59 \\
Sigara Kullanımı & 9.05 & 5.74 & 2.11 & 3.56 \\
İntihar Eğilimi & 12.16 & 3.09 & 0.07 & 0.05 \\
Beslenme Alışkanlıkları & 14.16 & 4.37 & 0.08 & -0.36 \\
Okul Terki & 10.57 & 5.74 & 2.26 & 5.09 \\
Akranlarla Geçirilen & 2.23 & 1.32 & 1.04 & 0.35 \\
Süre (Saat) & & & & \\
\hline
\end{tabular}


Değişkenlerin çarpıklık basıklık katsayısı incelendiğinde doğrudan akran baskısı, dolaylı akran baskısı, antisosyal davranışlar, intihar eğilimi ve beslenme alışkanlıkları değişkenlerinin çarpıklık basıklık katsayılarının -1.5 ve +1.5 aralığında olduğu görülmüştür. Ancak alkol kullanımı, sigara kullanımı ve okul terki değişkenlerinin çarpıklık basıklık katsayılarının -1.5 ve +1.5 aralığında olmadığı gözlenmiştir. Çarpıklık basıklık kat sayısı -1.5 ve +1.5 aralığında olan değişkenler normal kabul edilmiştir parametrik testler uygulanmıştır. Bu aralığın dışındaki değerler için nonparametrik testler uygulanmıştır (Tabachnick ve Fidell, 2013).

\section{Ergenlerde Akran Baskısı ve Riskli Davranışlar Arasındaki İlişki}

Akran baskısı (doğrudan ve dolaylı) ve riskli davranışlar (anti sosyal davranışlar, intihar eğilimi ve beslenme alışkanlıkları) arasındaki ilişkinin ortaya konması için Pearson Momentler Çarpımı Korelasyon Katsayısı (r); akran baskısı (doğrudan ve dolaylı) ve riskli davranışlar (alkol kullanımı, sigara kullanımı ve okul terki) arasındaki ilişkinin ortaya konması için Spearman Brown Sıra Farkları Korelasyon Katsayısı $\left(\mathrm{r}_{\mathrm{s}}\right)$ kullanılmıştır. Korelasyon analizi sonuçları Tablo 2'de verilmiştir.

Tablo 2

Korelasyon Analizi Sonuçları (N=392)

\begin{tabular}{|c|c|c|c|c|c|c|c|c|}
\hline & 1. & 2. & 3. & 4. & 5. & 6. & 7. & 8. \\
\hline $\begin{array}{l}\text { 1. Doğrudan Akran } \\
\text { Baskısı }\end{array}$ & 1 & $0.57 *$ & $0.26^{*}$ & $0.24 *$ & $0.17 *$ & $0.22 *$ & $0.32 *$ & $0.41^{*}$ \\
\hline $\begin{array}{l}\text { 2. Dolaylı Akran } \\
\text { Baskis1 }\end{array}$ & & 1 & $0.42 *$ & $0.25^{*}$ & $0.23 *$ & $0.25^{*}$ & $0.30^{*}$ & $0.42 *$ \\
\hline $\begin{array}{l}\text { 3. Antisosyal } \\
\text { Davranışlar }\end{array}$ & & & 1 & $0.43^{*}$ & $0.37 *$ & $0.32 *$ & $0.40^{*}$ & $0.41^{*}$ \\
\hline 4. İntihar Eğilimi & & & & 1 & $0.33 *$ & $0.08 * *$ & $0.24 *$ & $0.31 *$ \\
\hline $\begin{array}{l}\text { 5. Beslenme } \\
\text { Alışkanlıkları } \\
\text { 6. Alkol Kullanımı }\end{array}$ & & & & & 1 & $0.18^{*}$ & $0.23 *$ & $0.23^{*}$ \\
\hline 6. Alkol Kullanımı & & & & & & 1 & 1 & $0.34 *$ \\
\hline 8. Okul Terki & & & & & & & & 1 \\
\hline
\end{tabular}

$* \mathrm{p}<0.05, \quad * * \mathrm{p}>0.05$

Tablo 2'deki bulgulara göre doğrudan akran baskısı ile dolaylı akran baskısı arasında orta düzeyde anlamlı bir ilişki olduğu görülmektedir $(\mathrm{r}=0.57, \mathrm{p}<0.05)$. Doğrudan akran baskısı ile antisosyal davranışlar arasında düşük düzeyde anlamlı bir ilişki $(\mathrm{r}=0.26, \mathrm{p}<.05)$, dolaylı akran baskısı ile antisosyal davranışlar arasında ise orta düzeyde anlamlı bir ilişki $(r=0.42, \mathrm{p}<0.05)$ olduğu görülmektedir. Tablonun devamı incelendiğinde doğrudan akran baskısı ile intihar eğilimi arasında düşük düzeyde anlamlı bir ilişki ( $r=0.24, \mathrm{p}<0.05)$, dolaylı akran baskısı ile intihar eğilimi arasında ise yine düşük düzeyde anlamlı bir ilişki $(\mathrm{r}=0.25, \mathrm{p}<0.05)$ olduğu görülmektedir.Tablonun son kısmı incelendiğinde doğrudan akran baskısı ile beslenme alışkanlıkları arasında düşük düzeyde anlamlı bir ilişki ( $\mathrm{r}=0.17, \mathrm{p}<0.05)$, dolaylı akran baskısı ile beslenme alışkanlıkları arasında ise düşük düzeyde anlamlı bir ilişki $(\mathrm{r}=0.23, \mathrm{p}<0.05)$ olduğu görülmektedir.

Doğrudan akran baskısı ile alkol kullanımı arasında düşük düzeyde anlamlı bir ilişki ( $r_{s}=0.22$, $\mathrm{p}<0.05)$, dolaylı akran baskısı ile alkol kullanımı arasında ise düşük düzeyde anlamlı bir ilişki $\left(\mathrm{r}_{\mathrm{s}}\right.$ $=0.25, \mathrm{p}<0.05$ ) olduğu görülmektedir. Tablonun devamı incelendiğinde doğrudan akran baskıs1 ile sigara kullanımı arasında orta düzeyde anlamlı bir ilişki $\left(\mathrm{r}_{\mathrm{s}}=0.32, \mathrm{p}<0.05\right)$, dolaylı akran baskısı ile sigara kullanımı arasında ise orta düzeyde anlamlı bir ilişki $\left(r_{s}=0.30, p<0.05\right)$ olduğu görülmektedir. Tablonun son kısmı incelendiğinde doğrudan akran baskısı ile okul terki arasında orta düzeyde anlamlı bir ilişki $\left(\mathrm{r}_{\mathrm{s}}=0.41, \mathrm{p}<0.05\right)$, dolaylı akran baskısı ile okul terki arasında ise orta düzeyde anlamlı bir ilişki $\left(\mathrm{r}_{\mathrm{s}}=0.42, \mathrm{p}<0.05\right)$ olduğu görülmektedir. 
Riskli davranışların birbirleri ile olan ilişkisi incelendiğinde ise riskli davranışların (intihar ve alkol kullanımı haricinde) birbirleri ile çeşitli düzeylerde pozitif yönde anlamlı ilişkiler gösterdiği görülmektedir.

\section{Ergenlerde Akran Baskısı ve Riskli Davranışların Cinsiyete Göre Farklılaşması}

Akran baskısı (doğrudan ve dolaylı) ve riskli davranışların (antisosyal davranışlar, intihar eğilimi ve beslenme alışkanlıkları) cinsiyete göre ortalamalarının farklılaşmasını ortaya koymak için ilişkisiz örneklemler için $\mathrm{t}$ test kullanılmıştır. $\mathrm{t}$ test sonuçları Tablo 3'de verilmiştir.

Tablo 3

Ergenlerde Akran Baskısı ve Riskli Davranışların Cinsiyete Göre t test Analizi Sonuçları (N=392)

\begin{tabular}{|c|c|c|c|c|c|c|c|}
\hline & Grup & $\mathrm{N}$ & Ortalama & $\begin{array}{c}\text { Standart } \\
\text { Sapma }\end{array}$ & $\mathrm{T}$ & $\mathrm{Sd}$ & $\mathrm{p}$ \\
\hline Doğrudan & Kadın & 199 & 20.97 & 2.9287 & -4.92 & 390 & $0.00 *$ \\
\hline $\begin{array}{l}\text { Akran } \\
\text { Bask1s1 }\end{array}$ & Erkek & 193 & 22.58 & 3.5125 & & & \\
\hline Dolaylı & Kadın & 199 & 19.76 & 5.2666 & -3.99 & 390 & $0.00 *$ \\
\hline $\begin{array}{l}\text { Akran } \\
\text { Bask1s1 }\end{array}$ & Erkek & 193 & 22.05 & 6.0791 & & & \\
\hline Antisosyal & Kadın & 199 & 13.75 & 5.4818 & -2.14 & 390 & $0.03 *$ \\
\hline Davranış & Erkek & 193 & 14.88 & 4.9001 & & & \\
\hline İntihar & Kadın & 199 & 12.29 & 2.9485 & 0.79 & 390 & $0.42 * *$ \\
\hline Eğilimi & Erkek & 193 & 12.04 & 3.2499 & & & \\
\hline Riskli & Kadın & 199 & 14.29 & 4.1643 & 0.52 & 390 & $0.52 * *$ \\
\hline $\begin{array}{l}\text { Beslenme } \\
\text { Alıskanlık. }\end{array}$ & Erkek & 193 & 14.01 & 4.5810 & & & \\
\hline
\end{tabular}

Tablo 3 incelendiğinde ergenlerde doğrudan akran baskısı puan ortalamalarının cinsiyete göre farklılaştığ 1 görülmektedir $\left(\mathrm{t}_{390}=-4.92, \mathrm{p}<0.05\right)$. Sonuçlar, erkek ergenlerin $\left(\overline{\mathrm{x}}_{\mathrm{E}}=22.58\right)$ kadın ergenlere $\left(\overline{\mathrm{x}}_{\mathrm{K}}=20.97\right)$ göre daha yüksek düzeyde doğrudan akran baskısına maruz kaldığına işaret etmektedir. Ergenlerde dolaylı akran baskısı puan ortalamalarının cinsiyete göre farklılaştığ görülmektedir $\left(\mathrm{t}_{390}=-\right.$ 3.99, $\mathrm{p}<0.05)$. Sonuçlar, erkek ergenlerin $\left(\overline{\mathrm{x}}_{\mathrm{E}}=22.05\right)$ kadın ergenlere $\left(\overline{\mathrm{x}}_{\mathrm{K}}=19.76\right)$ göre daha yüksek dolaylı akran baskısına maruz kaldığına işaret etmektedir. Ergenlerde antisosyal davranış puan ortalamalarının cinsiyete göre farklılaştığ 1 görülmektedir $\left(\mathrm{t}_{390}=-2.14, \mathrm{p}<0,05\right)$. Sonuçlar, erkek ergenlerin $\left(\overline{\mathrm{x}}_{\mathrm{E}}=14.88\right)$ kadın ergenlere $\left(\overline{\mathrm{x}}_{\mathrm{K}}=13.75\right)$ göre daha yüksek antisosyal davranış eğilimi taşıdığına işaret etmektedir. Ergenlerde intihar eğilimi puan ortalamaları $\left(\mathrm{t}_{390}=0.79, \mathrm{p}>0.05\right)$ ile riskli beslenme davranışı puan ortalamalarının $\left(\mathrm{t}_{390}=0.52, \mathrm{p}>0.05\right)$ cinsiyete göre farklılaşmadığ görülmektedir.

Riskli davranışların (alkol kullanımı, sigara kullanımı ve okul terki) cinsiyete göre farklılaşmasını ortaya koymak için Mann Whitney U testi kullanılmıştır. Mann Whitney U testi sonuçları Tablo 4'te verilmiştir.

Tablo 4

Ergenlerde Riskli Davranuşların Cinsiyete Göre Mann Whitney U Testi Sonuçları $(N=392)$

\begin{tabular}{lccccccc}
\hline & Grup & $\mathrm{N}$ & Sira Orta. & Sira Top. & $\mathrm{U}$ & $\mathrm{z}$ & $\mathrm{P}$ \\
\hline Alkol & Kadın & 199 & 180.49 & 35917.50 & 16017.50 & -4.535 & $0.00^{*}$ \\
& Erkek & 193 & 213.01 & 41110.50 & & & \\
Sigara & Kadın & 199 & 174.03 & 34631.00 & 14731.00 & -4.536 & $0.00^{*}$ \\
& Erkek & 193 & 219.67 & 42397.00 & & & \\
\multirow{2}{*}{ Okul Terki } & Kadın & 199 & 172.99 & 34425.00 & 14525.00 & -4.369 & $0.00^{*}$ \\
& Erkek & 193 & 220.74 & 42603.00 & & & \\
\hline
\end{tabular}

$* p<0.05, \quad * * p>0.05$ 
Tablo 4 incelendiğinde ergenlerde alkol kullanım riskinin cinsiyete göre farklılaştığı görülmektedir $(\mathrm{U}=16017.50, \mathrm{z}=-4.535, \mathrm{p}<0.05)$. Sonuçlar, erkek ergenlerin (Sıra Orta.:213.01) kadın ergenlere (Sıra Orta.:180.49) göre daha yüksek düzeyde alkol tüketimi davranışı gösterdiğine işaret etmektedir. Ergenlerde sigara kullanım riskinin cinsiyete göre farklılaştığı görülmektedir ( $U$ = 14731.00, $\mathrm{z}=-4.536, \mathrm{p}<0.05$ ). Sonuçlar, erkek ergenlerin (Sıra Orta.:219.67) kadın ergenlere (Sıra Orta.:174.03) göre daha yüksek düzeyde sigara tüketimi davranışı gösterdiğine işaret etmektedir. Ergenlerde okul terki riskinin cinsiyete göre farklılaştığı görülmektedir $(U=14731.00, z=-4.369$, $\mathrm{p}<0.05$ ). Sonuçlar, erkek ergenlerin (Sıra Orta.:220.74) kadın ergenlere (Sıra Orta.:172.99) göre daha yüksek düzeyde okul terki davranışı gösterdiğine işaret etmektedir.

\section{Ergenlerde Akran Baskısı ve Riskli Davranışların Akranlarla Geçirilen Süreyle İlişkisi}

Akran baskısı (doğrudan ve dolaylı) ile riskli davranışların (anti sosyal davranış, alkol kullanımı, sigara kullanımı, intihar, riskli beslenme davranışları ve okul terki) akranlarla geçirilen okul dışı süre arasındaki ilişkinin ortaya konması için Spearman Brown Sıra Farkları Korelasyon Katsayısı $\left(\mathrm{r}_{\mathrm{s}}\right)$ kullanılmıştır. Korelasyon Analizi sonuçları Tablo 5’te verilmiştir.

Tablo 5

Ergenlerde Akran Baskısı ve Riskli Davranışların Akranlarla Geçirilen Süre Korelasyon Analizi Sonuçları $(N=388)$

\begin{tabular}{lcccccccc}
\hline & $\begin{array}{c}\text { Doğrudan } \\
\text { Akran } \\
\text { Baskıs1 }\end{array}$ & $\begin{array}{c}\text { Dolaylı } \\
\text { Akran } \\
\text { Baskıs1 }\end{array}$ & $\begin{array}{c}\text { Antisosyal } \\
\text { Davranış }\end{array}$ & $\begin{array}{c}\text { Alkol } \\
\text { Kulla. }\end{array}$ & $\begin{array}{c}\text { Sigara } \\
\text { Kulla. }\end{array}$ & $\begin{array}{c}\text { İntihar } \\
\text { Eğilimi }\end{array}$ & $\begin{array}{c}\text { Beslenme } \\
\text { Alıs. }\end{array}$ & $\begin{array}{c}\text { Okul } \\
\text { Terki }\end{array}$ \\
\hline $\begin{array}{l}\text { Akranlarla } \\
\text { Geçirilen } \\
\text { Süre }\end{array}$ & $0.08^{* *}$ & $0.15^{*}$ & $0.19^{*}$ & $0.16^{*}$ & $0.16^{*}$ & $0.01 * *$ & $0.10^{*}$ & $0.12^{*}$ \\
\hline *p $<0.05, \quad * * p>0.05$ & & & & & & &
\end{tabular}

Tablo 5'de bulunan korelasyon analizi sonuçları incelendiğinde gözlenmektedir ki akranlar ile okul dışında geçirilen süre ile dolaylı akran baskısı $\left(\mathrm{r}_{\mathrm{s}}=0.15, \mathrm{p}<0.05\right)$, antisosyal davranış $\left(\mathrm{r}_{\mathrm{s}}=0.19\right.$, $\mathrm{p}<0.05)$, alkol kullanımı $\left(\mathrm{r}_{\mathrm{s}}=0.16, \mathrm{p}<0.05\right)$, sigara kullanımı $\left(\mathrm{r}_{\mathrm{s}}=0.16, \mathrm{p}<0.05\right)$, beslenme alışkanlıkları $\left(r_{s}=0.10, p<0.05\right)$ ve okul terki $\left(r_{s}=0.10, p<0.05\right)$ arasında düşük düzeyde pozitif yönde anlamlı ilişki bulunmaktadır. Ancak yapılan analiz sonucunda akranlarla okul dışında geçirilen süre ile doğrudan akran baskısı $\left(\mathrm{r}_{\mathrm{s}}=0.08, \mathrm{p}>0.05\right)$ ve intihar eğilimi $\left(\mathrm{r}_{\mathrm{s}}=0.01, \mathrm{p}>0.05\right)$ arasında anlamlı ilişki bulunmamıştır.

\section{Sonuç, Tartışma ve Öneriler}

Araştırma sonucunda elde edilen bulgulara göre ergenlerde akran baskısı ile riskli davranışlar arasında düşük ve orta düzeyde pozitif anlamlı ilişkiler bulunmaktadır. Bu bulgular literatürdeki Daniel (2016), Eyberg ve McDiarmid, (2005), Manzoni, Lotar ve Ricijas (2011) ve Wickert (2002) tarafından yapılan ve akran baskısının riskli davranışları artırdığına yönelik araştırma bulgularıyla benzerlik göstermektedir.

$\mathrm{Bu}$ ilişkiler doğrudan akran baskısında antisosyal davranış, intihar eğilimi, beslenme alışkanlıkları ve alkol kullanımında düşük düzeyde pozitif iken sigara kullanımı ve okul terkinde orta düzeyde pozitiftir. Bunun yanında dolaylı akran baskısının intihar eğilimi, beslenme alışkanlıkları ve alkol kullanımında düşük düzeyde pozitif bir ilişki görülürken antisosyal davranışta, sigara kullanımında ve okul terkinde orta düzeyde pozitiftir. Bulgular incelendiğinde antisosyal davranışların haricindeki doğrudan ve dolaylı akran baskısının diğer riskli davranışlarla benzer şekilde ilişkili olduğu tespit edilmiştir.

Diğer yandan araştırma sonucunda elde ettiğimiz riskli davranışlardan olan sigara ve alkol kullanımının doğrudan ve dolaylı akran baskısı ile olan ilişkisinde sigara kullanımında orta alkol kullanımın da ise düşük düzeyde pozitif bir ilişki tespit edilmiştir. Elde edilen bu bulgular literatürde Kıran Esen (2003) ve Satan (2011) tarafından yapılan araştırma bulgularıyla benzerlik göstermektedir. 
Ayrıca bu sonuç Chımwamurombe (2011) tarafindan yapılan araştırmada alkol, sigara, uyuşturucu gibi davranışların ergenler tarafından olumsuz olarak bilinmelerine rağmen bu davranışların yapılmaya devam edilmesinin nedeninin bu konudaki bilgi eksikliğinden değil de akran baskısı gibi bir faktör yüzünden ortaya çıktığı bulgularıyla da benzerlik göstermektedir. Bu durum sigaranın alkole göre daha kolay ulaşılabilir ve bulundurulabilir olmasından ve ayrıca yaygın inanış olarak sigara tüketimin alkol tüketimine nazaran daha az zararlı görülmesinden kaynaklanması olarak da yorumlanabilir.

Araştırma sonucunda elde bulgularından olan doğrudan akran baskısının antisosyal davranış, intihar eğilimi, beslenme alışkanlıkları ve alkol kullanımında düşük düzeyde pozitif yönde ilişkili iken, sigara kullanımı ve okul terkinde orta düzeyde pozitif yönde ilişkili olduğu tespit edilmiştir. Bunun yanında dolaylı akran baskısının intihar eğilimi, beslenme alışkanlıkları ve alkol kullanımında düşük düzeyde pozitif yönde bir ilişkisi görülürken antisosyal davranışta, sigara kullanımında ve okul terkinde ise orta düzeyde pozitif yönde ilişkisi olduğu tespit edilmiştir. Bu sonuç literatürde Alikaşifoğlu ve Ercan (2009), Gül ve Güneş (2009) ve Scott (2007) tarafindan yapılan ve ergenlerde akranlar arası baskının artması durumda alkol ve sigara kullanımı, intihar olasılığı, antisosyal davranışlar ve okul terki olasılı̆̆ının arttığını ortaya koyan araştırma bulgularıyla benzerlik göstermektedir. Bu durum ergenlerin bağlı oldukları akran grubunun bir üyesi olma ve grup içinde bu tarz davranışların yüceltilen davranışlar olması ve akran gruplarında risk almayan bireylerin korkak, ezik vb. ifadeler ile nitelendirilmesi ve gruptan dışlanma kaygısıyla ergenlerin bu tür baskılara boyun eğip riskli davranışlara uyması olarak yorumlanabilir.

Araştırma sonuçlarından elde edilen bir diğer bulgu dolaylı akran baskısının antisosyal davranışla olan ilişkisinin doğrudan akran baskısına göre daha yüksek olduğudur. $\mathrm{Bu}$ durum ergenlerde ortaya çıkan antisosyal davranışların akranların doğrudan baskısından çok dolaylı baskısı ile ortaya çıktığı anlamına gelebilmektedir. Bu sonuç literatürde Webber (1997) tarafından yapılan ve akran baskısının antisosyal davranışlarda artışa neden olduğunu ortaya koyan araştırma sonuçlarıyla benzerlik görülmektedir. Aynı zamanda bu bulgu ergen akran gruplarındaki dolaylı baskının daha yüksek derecede şiddet eğilimli antisosyal davranışlara zemin oluşturduğu şeklinde yorumlanabilir. Bu açıdan antisosyal davranışlar içinde akranlar arası model almayı ve örtük mesajları incelemek faydalı olabilir.

Araştırmanın değişkenlerinden olan cinsiyet faktörünün akran baskısı ile riskli davranışlar arasındaki ilişkisin ortaya koyan bulgulara göre sigara ve alkol kullanımı, okul terki ve antisosyal davranış, erkeklerde kadınlara göre anlamlı düzeyde daha yüksek olduğu tespit edilmiştir. Bu sonuç literatürdeki Aras, Günay, Özan ve Orcin (2007) ile Uludağlı ve Say1l (2009) tarafindan gerçekleştirilen ve erkek ergenlerin risk alma davranışının, kadın ergenlere göre daha yüksek olduğunu ortaya koyan araştırma bulgularıyla benzerlik göstermektedir. Bu durum erkeklere ilişkin toplumsal cinsiyet rolleri beklentisine parelel olarak toplumda oluşan algilarında etkisiyle erkeklerin kadınlardan daha fazla cesur davranışlar gösterme eğilimlerinin olması ve özellikle de toplumda bir takım kültürel söylencelerin erkeklerdeki birtakım riskli davranışları daha destekleyici ve özendirici olması ile yorumlanabilir.

Diğer yandan araştırma bulgularında cinsiyete ilişkin elde edilen bir diğer sonuç ise intihar eğilimi ve riskli beslenme alışkanlıklarının cinsiyete göre farklılaşmadığını gösteren bulgular üzerinedir. Bu sonuç literatürdeki özellikle Ceyhun ve Ceyhun (2003), Chımwamurombe (2011), Ünlü, Aksoy ve Ersan (2014) tarafından yapılan ve cinsiyetle intihar ve beslenme davranışları üzerine akran baskısının etkisini gösteren araştırma bulgularıyla farklılık göstermektedir. Bu durum Siyez'e (2006) göre girişim düzeyindeki intihar davranışı ile gerçekleşen intihar davranışlarının cinsiyete göre farklılaştı̆g bu durumunda intihar davranışının ve eğilimin cinsiyet açısından daha tam olarak netleşmediği yönünde açıklanabilir. Bu açıdan intihar eğilimi ve intihar girişimi arasında bu fark dikkate alınarak ayrıca araştırılmalı ve bu iki kavramın cinsiyete göre değişimi daha detaylı olarak ele alınıp incelenmelidir.

Ayrıca araştırma bulgularına göre kadın cinsiyetine göre erkek cinsiyetinde olmak akran baskısına maruz kalma düzeyini arttıran bir faktör olarak bulunmuştur. Bu sonuçlar literatürde 
Kapıkıran ve Fiyakalı (2005) ile Satan (2011) tarafından gerçekleştirilen araştırma bulgularıyla benzerlik göstermektedir. Bu durum erkeklerin akran grupları içinde daha fazla akran baskısı gördüğü veya daha fazla akran baskısına açık olduğu anlamında yorumlanabilir. Bunun yanında erkek cinsiyeti akran gruplarında baskının normalleşmiş olma olasılığı akla gelmektedir. Ancak konu ile ilgili yapılacak farklı türdeki araştırmalar bu durumu daha da açığa kavuşturacaktır.

Araştırmanın bir diğer değişkenlerinden olan akranlarla okul dışında geçirilen süre ile akran baskısı ve riskli davranışlar arasındaki ilişkiye yönelik bulgularda ise alkol ve sigara kullanımı beslenme alışkanlıkları, okul terki ve antisosyal davranışlar, akranlarla geçirilen süre ile anlamlı bir ilişki gösterirken intihar davranışı için anlamlı bir ilişki tespit edilememiştir. Akranlarla okul dışında geçirilen süre ile akran baskısı ve riskli davranışlar arasında literatürde yapılan genel bir çalışmaya rastlanılamamıştır. Ancak literatürde intihar eğilimi özelinde yapılan bazı araştırmalar yalnız kalma ile intihar arasında ilişki olduğuna dair birtakım bulgular vermektedir. Örneğin bu konuda Eskin (2001) tarafından yapılan bir araştırmada yalnızlığın intihar eğilimini arttırdığı tespit edilmiştir. Bu durum intihar eğilimin yalnızlaşma ile arttığı önermesini desteklemektedir.

Diğer yandan akranlar ile geçirilen süre ile dolaylı akran baskısı pozitif yönde ilişki gösterirken doğrudan akran baskısı ile anlamlı bir ilişki göstermemektedir. Bu sonuç literatürde Nivea (2006) tarafından gerçekleştirilen araştırma bulgularıyla benzerlik göstermektedir. Bu durum ergenlerin doğrudan akran baskısı gördüğü durumlarda akranlarıyla geçirilen sürenin anlamlı olarak değişmediği ancak dolaylı akran baskısı gördüğü durumlarda akranlar ile yakınlaştığı ve daha fazla vakit geçirdiği şeklinde yorumlanabilir. Bununla birlikte bulgularda ve tartışmanın önceki kısımlarında belirtildiği gibi dolaylı akran baskısı ile başta antisosyal davranışları olmak üzere diğer riskli davranışlar arasında doğrudan akran baskısına göre daha yüksek ilişkili bir yapı göstermektedir. $\mathrm{Bu}$ iki durum beraber değerlendirildiğinde dolaylı akran baskısının ne derece riskli olduğu gözlenmektedir.

Sonuç olarak araştırma bulguları bir bütün olarak incelendiğinde gözlenmektedir ki ergenlik döneminde akran ilişkileri ergen davranışlarını yönlendiren; özelilikle de riskli davranışların yaygınlaşmasında önemli bir faktör olarak değerlendirilebilir.

Araştırmadan elde edilen sonuçlara dayalı olarak aşağıda bir dizi önerilere yer verilmiştir.

- Riskli davranışların bireyler üzerindeki olumsuz etkilerini konu alan seminer, konferans gibi çeşitli etkinlikler düzenlenebilir. Bu konuda kitle iletişim ve sosyal medya kanalları kullanılarak öğrencilerin konuyla ilgili bilgilendirmeleri sağlanabilir.

- Ergenlerde riskli davranışları etkileyebilecek akranlar dışındaki diğer rol-model faktörlere yönelik bir dizi çalışmalar planlanabilir.

- Ayrica okullarda rol model olarak öğrenciyi doğrudan etkileme gücü olan öğretmenlerin görünür alanlardaki sigara tüketimlerine bir dizi yasaklamalar getirilebilir.

- Okullarda akran baskısına maruz kalan öğrencilere rehberlik servislerince psiko-eğitim programları planlanabilir.

- Sınıf içi rehberlik etkinlikleri kapsamında akran baskısı ve riskli davranışların olumsuz etkilerini konu alan etkinliklere yer verilebilir.

- Temel eğitimden başlamak üzere öğrencilere uyma davranışlarındaki koşulsuz sorgulamadan itaat etme yerine sorgulama ve gerektiğinde hayır diyebilme becerileri eğitimleri verilebilir. 
- Gelecekte yapılacak araştırmalarda özellikle gözlenmesi daha zor olan ve etkisinin daha fazla olduğu düşünülen dolaylı akran baskısına yönelik detaylı araştırmaların yapılması önerilebilir.

- $\mathrm{Bu}$ araştırma lisede öğrenim gören ergenlerle, cinsiyet ve okul dişında birlikte geçirilen süre değişkenleriyle sınırlı olduğundan gelecekte ortaokul düzeyindeki öğrencileri ve farklı değişkenleri kapsayacak çalışmalar yapılması önerilebilir.

Açıklama: Bu araştırma için Malatya İli İl Milli Eğitim Müdürlüğünün 11.03 .2020 tarihli Anket-Tez Araştırma ve Değerlendirme Komisyonu etik uygunluk kararı ve 61316475-44-E.5459251 sayılı olur'u ile anket uygulaması etik izni alınmıştır. Araştırma sürecinin tamamında tüm bilimsel araştırma ve yayın etiğine uyulmuştur.

\section{Kaynaklar}

Aktuğ, T. (2006). Ergenlerde akran baskısı ve benlik saygısının incelenmesi. Yüksek Lisans Tezi. Mersin Üniversitesi, Sosyal Bilimler Enstitüsü, Mersin.

Alikaşifoğlu, M. ve Ercan, O. (2009). Ergenlerde riskli davranışlar. Turk Pediatri Arsivi, 44(1), 1 - 6.

Aras, S., Günay, T., Özan, S. ve Orcin, E. (2007). İzmir ilinde lise ögrencilerinin riskli davranışları. Anadolu Psikiyatri Dergisi, 8(3),186-196.

Austin, V. L. and Sciarra, D. T. (2017). Çocuk ve ergenlerde duygusal ve davranışsal bozukluklar (Çev. Ed. M. Özekes). Ankara: Nobel Yayınları.

Bayhan, P. ve Işıtan, A. G. S. (2010). Ergenlik döneminde ilişkiler: Akran ve romantik ilişkilere genel bakış. Sosyal Politika Çalışmaları Dergisi, 20(20),33-44.

Berndt, T. J. and Ladd, G. W. (1989). Peer relationships in child development. John Wiley \& Sons: Hoboken.

Büyüköztürk, Ş. (2017). Veri analizi el kitabı (23. baskı). Ankara: Pegem Akademi Yayıncılık.

Büyüköztürk, Ş., Çokluk, Ö. ve Köklü, N. (2016). Sosyal bilimler için istatistik (18. Baskı). Ankara: Pegem Akademi Yayıncılık.

Büyüköztürk, Ş., Kılıç Çakmak, E., Akgün, Ö. E., Karadeniz, Ş. ve Demirel, F. (2016). Bilimsel araştırma yöntemleri (22. baskı). Ankara: Pegem Akademi Yayıncılık.

Ceyhun, A. G. ve Ceyhun, B. (2003). Lise ve üniversite öğrencilerinde intihar olasılı̆̆ının değerlendirilmesi. Klinik Psikiyatri, 6(2),217-224.

Chimwamurombe, M. (2011). The influence of peer pressure on adolescent misbehaviour in schools. Doctoral Dissertation. University of the Western Cape, Cape Town.

Clasen, D. R. and Brown, B. B. (1985). The multidimensionality of peer pressure in adolescence. Journal of Youth and Adolescence, 14(6),451-468.

Daniel, K. E. (2016, April 20). The effect of peer presence on adolescent risk-taking behaviors. 24.03.2020 tarihinde https://digitalcommons.georgiasouthern.edu/honors-theses/181/ adresinden erişilmiştir. 
De Goede, I. H., Branje, S. J. and Meeus, W. H. (2009). Developmental changes and gender differences in adolescents' perceptions of friendships. Journal of Adolescence, 32(5), 11051123.

Dornbusch, S. M. (1989). The sociology of adolescence. Annual Review of Sociology, 15(1), 233-259.

Esen, B. K. (2003). Akran baskısı, akademik başarı ve yaş değişkenlerine göre lise öğrencilerinin risk alma davranışının yordanması. Hacettepe Üniversitesi Eğitim Fakültesi Dergisi, 24(24), 7985.

Eskin, M. (2001). Ergenlikte yalnızlık, baş etme yöntemleri ve yalnızlığın intihar davranışı ile ilişkisi. Klinik Psikiyatri, 4(5),5-11.

Eyberg, S. M. and McDiarmid, M. D. (2005). Parent-child interaction therapy. in A. M. Gross and R. S. Drabman (Eds.), Encyclopaedia of behaviour modification and cognitive-behaviour therapy (p. 940-944). Thousand Oaks, CA: Sage.

Gençtanırım, D. ve Ergene, T. (2014). Riskli davranışlar ölçeğinin geliştirilmesi: Geçerlik ve güvenirlik çalışmaları. International Journal of Social Science, 25(1),125-138.

Gül, S. K. ve Güneş, İ. D. (2009). Ergenlik dönemi sorunları ve şiddet. Sosyal Bilimler Dergisi, 11(1),79-101.

Kapıkıran, N. A. ve Fiyakalı, C. (2005). Lise öğrencilerinde akran baskısı ve problem çözme. Pamukkale Üniversitesi Eğitim Fakültesi Dergisi, 18(18),11-17.

Karasar, N. (2018). Bilimsel araştırma yöntemleri (33. baskı). Ankara: Nobel Yayınc1lık.

Kıran-Esen, B. (2003). Akran baskısı ölçeği’nin geliştirilmesi: geçerlik ve güvenirlik çalışması. Eğitim Bilimleri ve Uygulama, 2(3),65-79.

Manzoni, M. L., Lotar, M. and Ricijaš, N. (2011). Peer pressure in adolescence. Saarbrücken: Lap Lambert Academic Publ.

Nivea, D. (2006, December 16). Peer pressure and teens. 20.03.2020 tarihinde http://www.adoptionarticlesdirectory.com/ArticlesUser/articles_view.php?editid1=Peer\%20Pr essure\%20and\%20Teens adresinden erişilmiştir.

Satan, A. (2011). Ergenlerde akran baskısı, benlik saygıs1 ve alkol kullanımı arasındaki ilişkilerin incelenmesi. M. Ü. Atatürk Ĕ̈itim Fakültesi Eğitim Bilimleri Dergisi, 34(1), 183-194.

Savin-Williams, R. C. and Berndt, T. J. (1990). Friendship and peer relations. Massachusetts: Harvard University Press.

Scott, D. L. (2007). Early rheumatoid arthritis. British Medical Bulletin, 81(1), 97-114.

Siyez, D. M. (2006). Ergenlik döneminde intihar girişimleri: bir gözden geçirme. Kastamonu Eğitim Dergisi, 14(2),413-420.

Şahin, Ş. ve Özçelik, Ç. (2016). Ergenlik dönemi ve sosyalleşme. Cumhuriyet Hemşirelik Dergisi, 5(1),42-49.

Şimşek, H. ve Çöplü, F. (2018). Lise öğrencilerinin riskli davranışlar gösterme düzeyleri ile okula bağlanma düzeyleri arasındaki ilişkinin incelenmesi, Ahi Evran Üniversitesi Sosyal Bilimler Enstitüsü Dergisi, 4(1),18-30. 
Tabachnick, G.B. and Fidell, L. (2013). LS fidell using multivariate statistics (sixth ed.), Boston: Pearson.

Uludağl1, N. P. ve Sayıl, M. (2009). Orta ve ileri ergenlik döneminde risk alma davranışı: Ebeveyn ve akranların rolü. Türk Psikoloji Yazıları, 12(23),14-24.

Ünlü, G., Aksoy, Z. ve Ersan, E. E. (2014). İntihar girişiminde bulunan çocuk ve ergenlerin değerlendirilmesi. Pamukkale Tip Dergisi, 7(3),176-183.

Vander Zanden, J. W., Crandell, T. L. and Crandell, C. H. (2000). Adolescence: Emotional and social development. in Vander Zanden, J. (Eds.), Developmental psychology, (p. 358-389). Boston: McGraw-Hill.

Webber, M. (1997). The development of moral values and behaviour in teenagers. in Clausen's, J.A. (Ed.). Socialization and Society. Boston: Little Brown Books.

Wickert, K. C. (2002). Friends, cliques, and peer pressure: Be true to yourself. Berkeley Heights: Enslow Publishers. 


\section{Extended Abstract}

\section{Introduction}

Adolescence is seen as a transition period in which conflicts and confusion occur at the highest level in human development. During this period, individuals experience sudden and intense changes both physically and psychologically. Individuals are now embarked on a journey of development that extends from childhood to one adulthood in these challenging changes. According to Kiran-Esen, it is observed that risk-taking behaviors increase as peer pressure increases in adolescents. This reveals that peer pressure is one of the important variables directing the risk behavior of adolescents. While the effect of peers on each other during adolescence is directly seen in some cases, in some cases it can be indirectly. While the direct effects of the peers are more commanding and in the form of command sentences, their indirect applications can be in the form of modeling and encouraging behavior. While direct peer pressure can be observed more easily, indirect peer pressure can be more difficult to observe. On the other hand, both direct and indirect peer pressure in adolescents differ significantly by gender. Being a male gender significantly increases peer pressure in adolescents. Peer groups' effects on adolescents can occur in many areas, and especially in cases where peer influence is negative, many behaviors and attitudes of adolescents are affected by this and this may cause a number of negative behaviors in adolescents. These behaviors, which are also called risky behaviors, also involve various risks in terms of social, emotional and physical development of the adolescent. As can be seen, peer relationships start to play a decisive role in adolescent's life with adolescence. Although peer groups are important in terms of adolescent development, they also increase risk factors in certain situations, and this can bring great dangers for adolescents. In this study, it is aimed to reveal the relationships between peer pressure and risky behaviors in adolescents in terms of various variables. From this aspect, it is thought that the study will make important contributions to the literature.

\section{Method}

In this research, relational screening pattern was used as a research model. The study group of the research consists of 392 students (199 girls, 193 boys) studying in 4 state high schools in Malatya in the 2019-2020 academic year. Random sampling method was used to determine the study group. Data in this research; Personal Information Form was collected using the Peer Pressure Scale and Risky Behavior Scale.

\section{Result}

According to the findings, there is a moderately significant positive relationship between direct peer pressure and indirect peer pressure. There is a low level of positive and significant relationship between direct peer pressure and antisocial behavior, a moderate positive and significant relationship between indirect peer pressure and antisocial behavior. When the continuation of the table is examined, there is a low positive and significant relationship between direct peer pressure and suicidal tendency, and a low positive and significant relationship between indirect peer pressure and suicidal tendency. When the last part of the table is examined, there is a low positive and significant relationship between direct peer pressure and nutritional habits, and a moderate positive and significant relationship between indirect peer pressure and nutritional habits.

There is a low level of positive and significant relationship between direct peer pressure and alcohol use, and a low level of positive and meaningful relationship between indirect peer pressure and alcohol use. When the continuation of the table is examined, there is a moderate positive and significant relationship between direct peer pressure and smoking, and a moderate positive and significant relationship between indirect peer pressure and smoking. When the last part of the table is examined, there is a moderate positive and significant relationship between direct peer pressure and school dropout, and a moderate positive and significant relationship between indirect peer pressure and school dropout. 


\section{Discussion and Conlusion}

According to the findings obtained as a result of the research, there are low and medium positive significant relationships between peer pressure and risky behavior in adolescents. These findings are similar to the findings of the research conducted by Daniel (2016), Eyberg and McDiarmid, (2005), Manzoni, Lotar and Ricijas (2011) and Wickert (2002) in the literature that peer pressure increases risky behaviors.

These relationships are low positive in antisocial behavior, suicidal tendencies, nutritional habits and alcohol use in peer pressure, and moderately positive in smoking and school dropout. In addition, there is a low positive correlation in the suicidal tendency, nutritional habits and alcohol use of indirect peer pressure, while it is moderately positive in antisocial behavior, smoking and school dropout. When the findings were examined, direct and indirect peer pressure other than antisocial behaviors were found to be similar to other risky behaviors.

While indirect peer pressure has a positive relationship with the time spent with peers, it does not show a significant relationship with direct peer pressure. This result is similar to the findings of the research conducted by Nivea (2006) in the literature. This situation does not significantly change the time spent with their peers in cases where adolescents experience direct peer pressure; however, it can be interpreted as getting closer with peers and spending more time in cases of indirect peer pressure. However, as stated in the findings and earlier parts of the discussion, it shows a higher correlation between indirect peer pressure and other risky behaviors, especially antisocial behavior, compared to direct peer pressure. When these two situations are evaluated together, it is observed how risky indirect peer pressure is. 